\title{
PERCEPÇÃO DA PROFUNDIDADE DE MÁSCARAS CÔNCAVAS BRANCA, CINZA-MÉDIO E PRETA
}

\author{
Esther Sampaio Santos \\ (Brock University. St. Catharines - Canadá) \\ Lívia da Silva Bachetti \\ (Universidade de São Paulo - USP - Ribeirão Preto - SP) \\ Maria Amélia Cesari Quaglia \\ (Universidade Federal de São João del-Rei - UFSJ - São João del-Rei - MG) \\ Branda Garcia da Silva \\ (Universidade Federal de São João del-Rei - UFSJ - São João del-Rei - MG) \\ Caio Rafael Silveira \\ (Universidade Federal de São João del-Rei - UFSJ - São João del-Rei - MG)
}

\section{Resumo}

O presente estudo objetivou investigar a percepção monocular da profundidade ou relevo de máscaras côncavas: branca, cinza-médio e preta, iluminadas por baixo e apresentadas nas posições vertical e invertida. Quarenta observadores estimaram a profundidade ou relevo dos reversos ocos das máscaras por meio de uma escala do tipo Likert e a profundidade métrica visualmente percebida, julgada por meio de uma trena retrátil. Não foram observadas diferenças nas atribuições métricas da profundidade ou relevo da máscara côncava frente às variações de e posicionamento e de luminosidade ou brilho. Houve tendências para perceber a máscara branca com maiores profundidades e a preta com menores durante a inversão monocular. Entretanto, maiores profundidades foram designadas às máscaras preta quando não foi percebida a ilusão.

Palavras-chave: Ilusão da máscara côncava; Percepção de faces; Percepção visual; Percepção de profundidade; Inversão visual da profundidade.

\section{Abstract \\ Depth Perception of White, Medium Gray and Black Masks}

This study aimed to investigate the monocular depth or relief perception of concave masks: white, gray-medium and black, illuminated from below and presented in vertical and inverted positions. Forty viewers estimated the depth or relief of the hollow reversals of the masks through a Likert-type scale and the visually perceived metric depth judged by means of a retractable track. No differences were observed in the metric assignments of the depth or relief of the concave mask regarding the variations of positioning and luminosity or brightness. There were tendencies to perceive the white mask with greater depths and the black with smaller ones during the monocular inversion. However, greater depths were assigned to the black mask when the illusion was not perceived.

Keywords: Hollow-mask illusion; Faces perception; Visual perception; Depth perception; Reversal of visual depth. 


\section{Introdução}

As ilusões são interpretações equivocadas de estímulos reais originárias dos mesmos mecanismos de funcionamento da percepção habitual. No entanto, são soluções perceptivas que denotam uma tentativa de correção de estímulos discrepantes (Baldo e Haddad, 2003). Schneider et al. (1996) indicaram que a percepção visual é o resultado da interação entre três fatores: sensoriais, cognitivos e adaptativos. Os processos relativos ao envio de sinais sensoriais ao cérebro são denominados de bottom-up, de baixa ordem, e provêm da estimulação visual do meio. Os processos cognitivos são denominados de top-down, de alta ordem, e estão relacionados a conhecimentos anteriores do indivíduo. Os pesquisadores propuseram ainda um terceiro fator, o adaptativo, que está ligado à tomada de decisões frente a situações ambíguas que requerem a interpretação do objeto observado. No entanto, as hipóteses perceptuais podem discordar entre si, no cérebro e, no caso da ilusão da máscara côncava, autores como Gregory (1997) propuseram que os processos cognitivos, top-down, se sobrepõem aos sensoriais, bottom-up. Uma hipótese aceitável para a explicação do fenômeno da máscara côncava é a de que a existência de faces côncavas é rejeitada pelo cérebro humano. Este possibilita a interpretação da imagem de acordo com o modo em que ela é apropriadamente apresentada, ou seja, com a forma convexa, voltada para fora.

A inversão visual da profundidade é uma ilusão visual que converte estímulos côncavos em perceptos convexos. O fenômeno da ilusão da máscara côncava é um exemplo de inversão visual da profundidade, caracterizado pela percepção de uma face convexa, voltada para fora, diante da apresentação do reverso côncavo ou oco de uma máscara análoga à da face humana. Essa ilusão está relacionada ao conhecimento e ao alto grau de familiaridade que o indivíduo tem em relação às faces que conhece no mundo natural (Gregory, 1997; Hill \& Bruce, 1993; Hill \& Johnston, 2007; Quaglia \& Fukusima, 2009). Como o homem é um animal filogeneticamente social, sua capacidade de reconhecer faces se constituiu em um aspecto essencial para a interação com os outros indivíduos, garantindo, desse modo, a preservação individual e a da espécie (Darwin, 1998).

Diversas condições de apresentação que podem favorecer $\mathrm{o}$ fenômeno da inversão visual da profundidade e, para investigar este fenômeno ilusório, pesquisadores têm utilizado diferentes 
metodologias na apresentação da máscara. Alguns estudos foram realizados com aproximações e afastamentos dos participantes até que ocorresse a inversão binocular da profundidade da máscara côncava apresentada objetivamente. Para Hill e Johnston (2007), a coloração da máscara com a tonalidade bege, natural, comparativamente com a máscara cinza facilitou a inversão visual da profundidade da mesma na investigação realizada. Nela, os participantes foram capazes de perceber a ilusão mesmo estando a uma pequena distância da máscara côncava, observada binocularmente. A orientação vertical da máscara côncava também facilitou a percepção ilusória comparativamente à máscara posicionada de cabeça para baixo, posto que os observadores precisassem estar mais afastados da mesma para perceberem a ilusão (Hill \& Johnston, 2007). Resultados semelhantes foram encontrados por Hill e Bruce (1993) e por Papathomas e Bono (2004), em que maiores distâncias entre os sujeitos e o objeto foram necessárias para que eles realizassem a inversão visual da profundidade da máscara côncava na posição invertida.

Os resultados apresentaram-se consistentes mesmo com a utilização de um procedimento diferente, como uma metodologia psicofísica de investigação e com a apresentação de projeções estereoscópicas de imagens da máscara côncava. Yoshida (2006) demonstrou que a ilusão da máscara côncava posicionada verticalmente, foi mais forte em comparação com a posição invertida. Quaglia e Fukusima (no prelo) também encontraram uma influência do posicionamento da máscara côncava na percepção ilusória. Ao comparar a atribuição de profundidade ou relevo em centímetros em estereogramas de máscaras côncavas na posição vertical e invertida, foram atribuídas as maiores profundidades ou relevo para as máscaras côncavas policromada e monocromada posicionadas verticalmente, independente da direção da fonte de luz incidente.

No entanto, a fonte de iluminação percebida como vinda de cima da cabeça também é apontada como um dos facilitadores do fenômeno da inversão visual de profundidade (Hill \& Johnston, 2007; Hill \& Bruce, 1993; Yoshida, 2006). Na ilusão da máscara côncava, a inversão da profundidade da máscara ocorre junto com a inversão da direção da fonte de iluminação incidente percebida. Desta forma, quando iluminada por baixo, a máscara côncava é percebida como convexa e iluminada por cima da cabeça, como a fonte de luz natural, proveniente do sol (Hill \& Bruce, 1993). A mesma 
ESTHER SAMPAIO SANTOS, LÍVIA DA SILVA BACHETTI, MARIA AMÉLIA CESARI QUAGLIA, BRANDA GARCIA DA SILVA, CAIO RAFAEL SILVEIRA

tendência foi encontrada quando investigadas as atribuições de centímetros às percepções ilusórias, no julgamento da profundidade de estereogamas da máscara côncava, da ponta do nariz até a sua base. Tanto a máscara côncava policromada quanto monocromada receberam maiores centímetros para profundidade percebida, quando iluminadas fisicamente por baixo, comparativamente às iluminadas por cima da cabeça (Quaglia \& Fukusima, no prelo).

Por outro lado, certas condições dificultam a realização da inversão visual da profundidade e a percepção da magnitude categórica da profundidade ou relevo da máscara côncava. Um desses fatores foi avaliado por Hill e Johnston (2007). Eles demonstraram que níveis elevados de ruído sobre a máscara côncava originavam as menores profundidades ou relevos percebidos. É possível que estes resultados tenham sido decorrentes da diminuição do brilho aparente da máscara côncava e não, necessariamente dos níveis de ruído apresentados sobre a superfície da máscara. Portanto, não existem pesquisas que investigaram diretamente se as diferentes condições de brilho aplicadas às máscaras côncavas interferem na percepção de sua profundidade ou relevo. Visando ampliar o corpo de conhecimento a respeito dessa temática, o presente estudo teve como objetivo geral investigar a inversão visual da profundidade e a percepção da profundidade ou relevo da máscara côncava em distintas condições de brilho. Teve ainda como objetivos específicos: (a) verificar se a magnitude do brilho (branco, cinza-médio e preto) interfere na inversão monocular e na magnitude percebida da profundidade ou relevo da máscara; (b) verificar a inversão visual da profundidade e a percepção da magnitude, categórica e métrica, da profundidade ou relevo de máscaras côncavas sob a condição de observação monocular e (c) investigar se a posição da máscara côncava (vertical e invertida) afeta a inversão monocular da profundidade e a magnitude percebida do relevo ou profundidade da máscara.

\section{Método}

\section{Participantes}

Participaram do estudo estudantes dos diferentes cursos de graduação e pósgraduação da Universidade Federal de São João del-Rei (UFSJ). Os participantes apresentaram acuidade visual normal ou corrigida de 6/6 na escala optométrica de Snellen e todos leram e assinaram o Termo de Consentimento Livre e Esclarecido. A amostra foi composta por 40 indivíduos, sendo 27 do sexo feminino $(67,5 \%)$ e 13 
do sexo masculino $(32,5 \%)$, com média de idade 24 anos $(D P=5,7)$. Os indivíduos da população-alvo que apresentavam diagnóstico de alguma comorbidade psiquiátrica grave, como esquizofrenia e abstinência alcoólica, estavam em privação prolongada de sono e fizessem uso abusivo de Cannabis Sativa, foram excluídos da composição da amostra.

\section{Material e equipamento}

Para avaliar a acuidade visual dos observadores foi utilizada a Tabela Optométrica de Snellen. Para avaliar a percepção visual da profundidade, foram utilizadas 3 máscaras côncavas confeccionadas a partir de cabeças de bonecas comerciais medindo $10 \mathrm{~cm}$ de altura, $6,5 \mathrm{~cm}$ de largura e $3 \mathrm{~cm}$ de profundidade, pintadas nas cores branca, cinza-médio, com refletância aproximada de 20\%, e preta. Como equipamento experimental foi utilizada uma caixa de madeira, do tipo MDF, de cor preta, medindo $37 \mathrm{~cm}$ de altura, $80 \mathrm{~cm}$ de largura e $37 \mathrm{~cm}$ de profundidade (Figura 1). Esta caixa possuía um visor, em uma das extremidades, com abertura de $0,5 \mathrm{~mm}$ de diâmetro, para possibilitar a observação monocular das máscaras côncavas que foram alocadas, uma por vez, na extremidade contralateral do visor. Em seu interior foi inserida uma lâmpada de $7 \mathrm{w}$ na parte inferior da caixa para iluminar a máscara por baixo. Para estimar, em centímetros, a profundidade ou relevo percebido das máscaras côncavas, os observadores utilizaram uma trena retrátil.

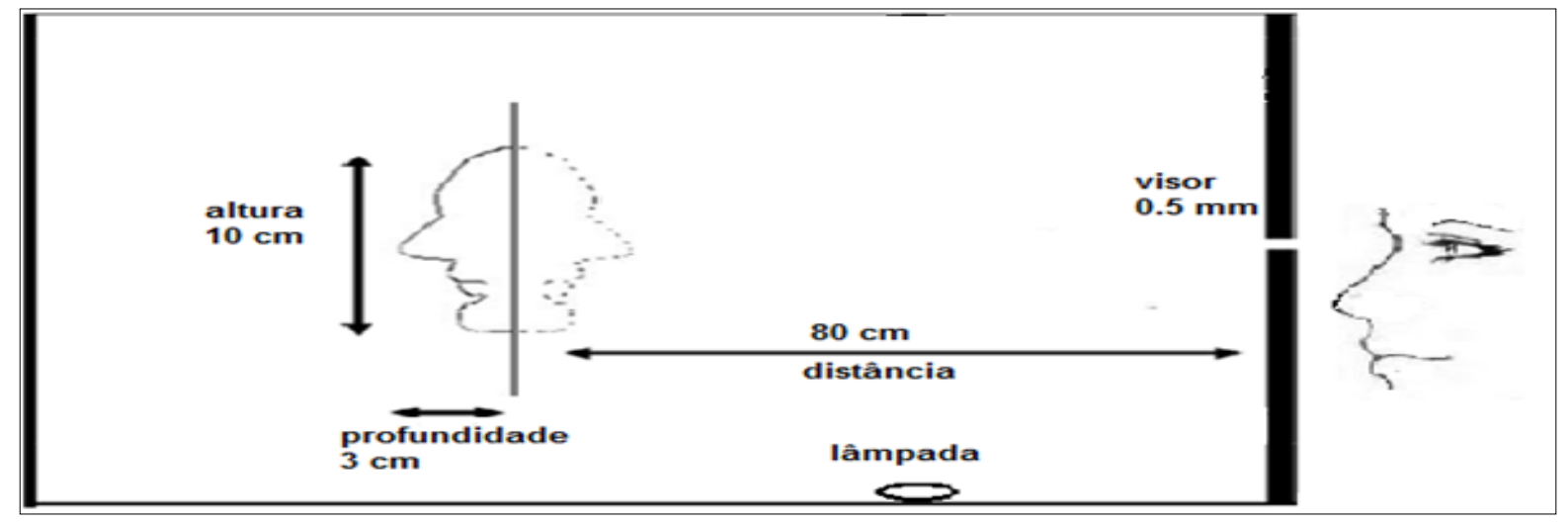

Figura 1. Desenho esquemático da caixa experimental, contendo em seu interior a máscara côncava. Adaptado de Quaglia e Fukusima (2009). 
ESTHER SAMPAIO SANTOS, LÍVIA DA SILVA BACHETTI, MARIA AMÉLIA CESARI QUAGLIA, BRANDA GARCIA DA SILVA, CAIO RAFAEL SILVEIRA

\section{Procedimento}

Os participantes receberam instruções e foram esclarecidos sobre os objetivos e procedimentos da pesquisa, em seguida leram e assinaram o Termo de Consentimento Livre e Esclarecido (TCLE). Após a assinatura do TCLE, os participantes tiveram a acuidade visual avaliada.

Individualmente, os participantes foram conduzidos até a sala experimental e instruídos a observar, através do visor da caixa, com o olho preferencial, a máscara côncava disponibilizada em seu interior. Em ordem aleatória, as máscaras côncavas foram apresentadas na posição vertical ou invertida, iluminadas por baixo da face. Em cada condição de apresentação do estímulo, foi solicitado ao observador que relatasse a profundidade ou relevo percebido da ponta do nariz da máscara à base da face da mesma em três tarefas.

$\mathrm{Na}$ primeira tarefa, foi solicitado ao participante que qualificasse a máscara como côncava ou convexa. A segunda tarefa constituiu em classificar categoricamente a profundidade ou relevo percebido da máscara côncava, dentre cinco categorias de uma escala Likert, respeitando o seguinte ordenamento: $1=$ totalmente côncava; $2=$ moderadamente côncava; $3=$ plana; $4=$ moderadamente convexa e $5=$ totalmente convexa. $\mathrm{Na}$ terceira tarefa, os observadores ajustaram, numa trena dimensionada em milímetros, a distância percebida entre a ponta do nariz e a base da máscara.

Considerações éticas

Este estudo foi aprovado pela Comissão de Ética em Pesquisa Envolvendo Seres Humanos (CEPES) da UFSJ em 20 de março de 2013, memorando $n^{\circ} \quad 024 / 2013 / C E P E S / U F S J$. Todos os participantes foram informados a respeito dos objetivos e procedimentos da pesquisa, da confidencialidade das respostas e da inexistência de respostas certas ou erradas. Foi informando também que a sua participação no estudo poderia ser interrompida a qualquer momento que desejasse.

\section{Resultados}

As análises estatísticas foram realizadas por meio do software Statistical Package for Social Sciences (SPSS), versão 20 , tendo por base o valor do nível de significância $p<0,05$. Para descrição da amostra foi realizada a análise estatística descritiva, com o cálculo das médias, dos erros-padrão e das porcentagens dos dados 
coletados. Foram analisados os dados referentes à frequência da realização ou não da inversão monocular da profundidade. Foi empregado o teste estatístico ANOVA de dois fatores para medidas repetidas, de modelo: 2 posições da máscara côncava x 3 máscaras côncavas com diferentes magnitudes de brilho, para verificar as diferenças entre os resultados dos observadores quanto às métricas da profundidade ou relevo da percebidos. Nesta análise, as condições relativas à posição e ao brilho da máscara côncava foram tomadas como fatores intrasujeitos. Também foi utilizado o pós-teste de Bonferroni com ajustamento para comparações múltiplas dos pares de médias dos fatores significativos e suas interações.

A Tabela 1 apresenta as frequências dos julgamentos como côncava, plana e convexa para cada uma das máscaras, nas diferentes posições de apresentação. Notase que a maioria dos observadores percebeu a máscara côncava como convexa em todas as condições experimentais. Quando observadas na posição vertical, as máscaras receberam maior número de atribuições para a categoria "convexa" nas três variações de brilho: branca $82,5 \%$, cinza-médio $80 \%$ e preta $62,5 \%$. Entretanto, a máscara côncava de cor preta apresentada na posição vertical foi percebida mais vezes como "plana", 10\%, e "côncava", 27,5\%, em comparação com a máscara branca e a cinza-médio. As máscaras côncavas posicionadas de cabeça para baixo receberam, em sua maioria, a classificação "convexa" para ambas as variações de brilho. Porém, foi encontrado um maior número de atribuiçõos para a categoria "côncava" nesta condição, independente do brilho da máscara: branca $32,5 \%$, cinza-médio $30 \%$ e preta $27,5 \%$. Fato interessante foi observado em relação a máscara côncava preta: o número de atribuições de concavidade foi o mesmo para as duas posições da máscara, vertical e invertida, 27,5\%. Além disso, as máscaras côncavas na posição invertida receberam um maior número de classificações para a categoria "plana", representando $15 \%$ das observações para todas as luminosidades ou brilho das máscaras. 
ESTHER SAMPAIO SANTOS, LÍVIA DA SILVA BACHETTI, MARIA AMÉLIA CESARI QUAGLIA, BRANDA GARCIA DA SILVA, CAIO RAFAEL SILVEIRA

\section{Tabela 1}

Frequências relativas (\%) dos julgamentos para as máscaras côncavas branca, cinza-médio e preta, como côncava (categorias 1 e 2), plana (categoria 3) e convexa (categorias 4 e 5) nas posições vertical e invertida.

\begin{tabular}{rrrrr}
\hline Posição & Categoria & Branca & Cinza-médio & Preta \\
\hline \multirow{2}{*}{ Vertical } & Côncavo & $15,0 \%$ & $15,0 \%$ & $27,5 \%$ \\
& Plano & $2,5 \%$ & $5,0 \%$ & $10,0 \%$ \\
& Convexo & $82,5 \%$ & $80,0 \%$ & $62,5 \%$ \\
\hline \multirow{2}{*}{ Invertida } & Côncavo & $32,5 \%$ & $30,0 \%$ & $27,5 \%$ \\
& Plano & $15,0 \%$ & $15,0 \%$ & $15,0 \%$ \\
& Convexo & $52,5 \%$ & $55,0 \%$ & $57,5 \%$ \\
\hline
\end{tabular}

A Figura 2 ilustra os resultados referentes às estimativas médias da profundidade ou relevo, em centímetros, da máscara côncava branca, considerando a distância da ponta do nariz da máscara até a base da face do estímulo. Os dados estão dispostos em função das categorias: totalmente côncava $(\mathrm{C} 1)$, moderadamente côncava (C2), plana (C3), moderadamente convexa (C4) e totalmente convexa (C5). Estão representadas todas as estimativas para a máscara côncava branca iluminada por baixo, totalizando 80 apresentações do estímulo. As maiores estimativas médias da profundidade métrica ocorreram quando a máscara branca foi apresentada na posição vertical, julgada como totalmente convexa (C5). As menores magnitudes médias da profundidade métrica estimada foram obtidas quando a máscara foi apresentada na posição vertical e classificada pelos observadores como plana (C3). 


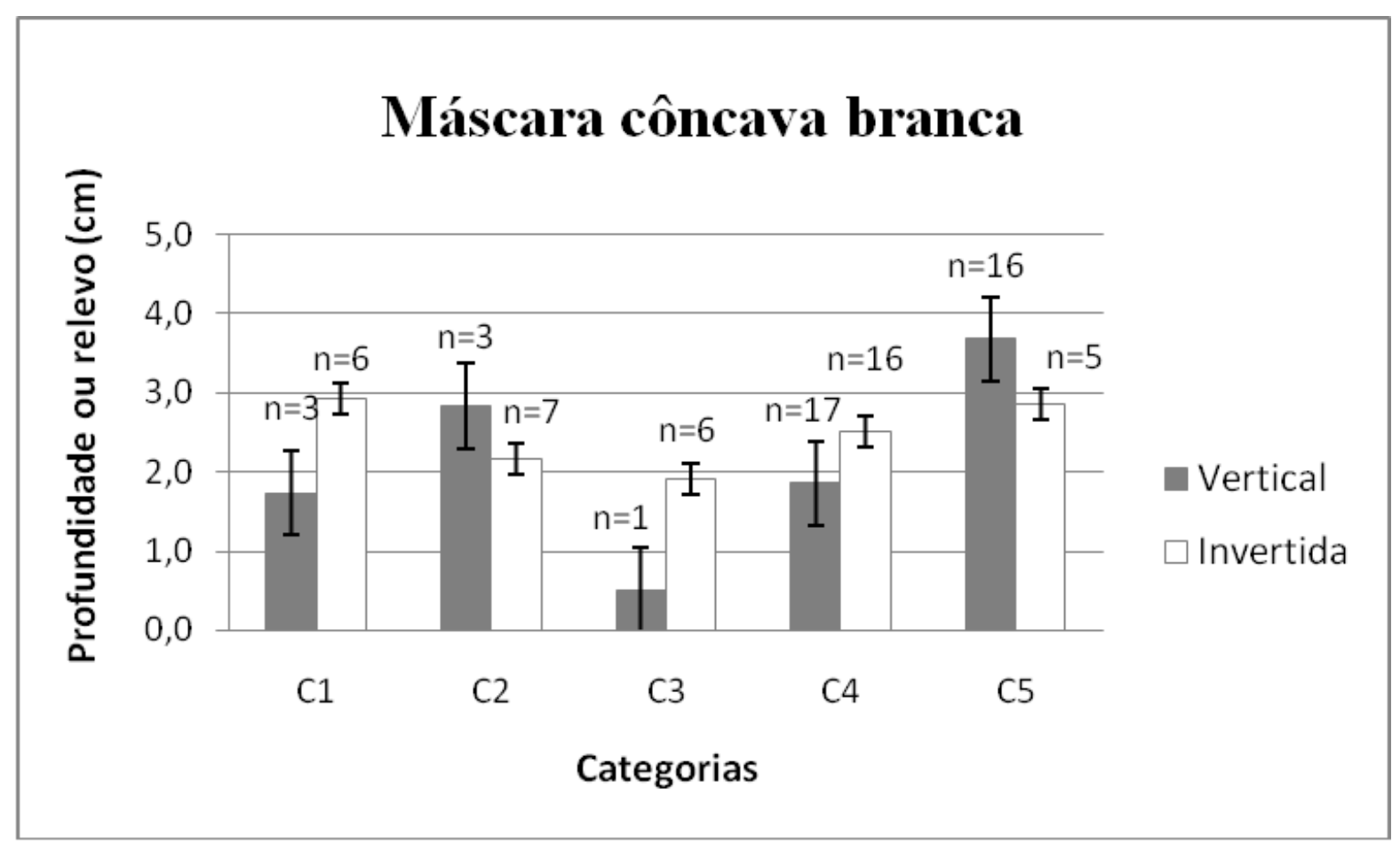

Figura 2. Estimativas médias, em centímetros, da profundidade ou relevo da máscara côncava branca para as categorias totalmente côncava (C1), moderadamente côncava (C2), plana (C3), moderadamente convexa (C4) e totalmente convexa (C5), em 80 apresentações do estímulo

$\mathrm{Na}$ Figura 3, estão dispostos os resultados referentes às estimativas médias, em centímetros, da profundidade ou relevo da máscara cinza-médio, apresentada nas posições vertical e invertida para cada uma das categorias de profundidade supracitadas. Estão representadas todas as estimativas para a máscara côncava cinza iluminada por baixo, totalizando 80 apresentações do estímulo. Observa-se que, diante da máscara cinza-médio apresentada na posição vertical, as maiores médias de profundidade métrica estimada foram obtidas quando a máscara foi apresentada na posição vertical e julgada como moderadamente côncava (C2). As menores profundidades, em média, foram atribuídas à máscara apresentada na posição vertical, julgada como plana. 


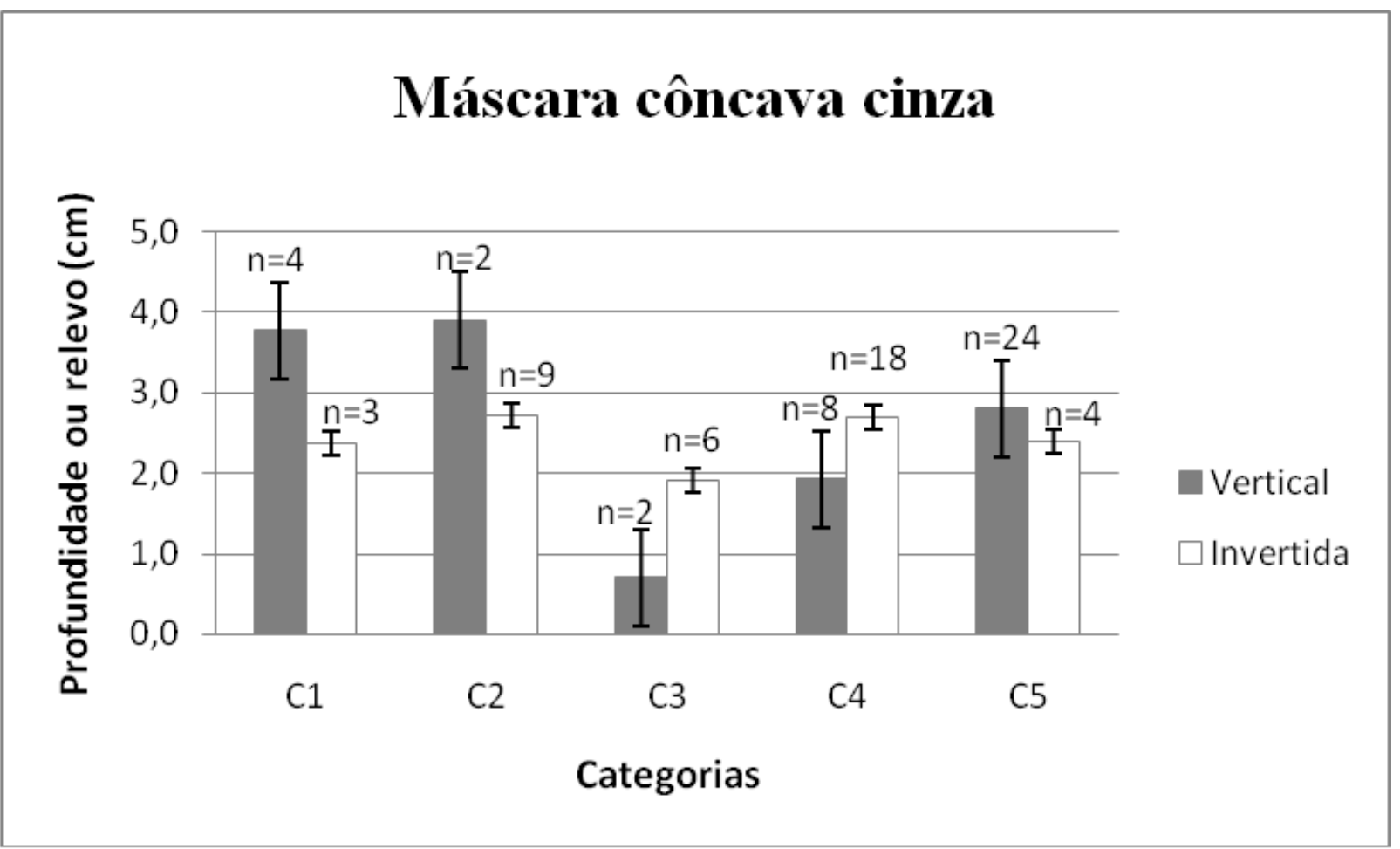

Figura 3. Estimativas médias, em centímetros, da profundidade ou relevo da máscara côncava cinza-médio para as categorias totalmente côncava (C1), moderadamente côncava (C2), plana (C3), moderadamente convexa (C4) e totalmente convexa (C5), em 80 apresentações do estímulo.

Dispõem-se, na Figura 4, os profundidade métrica estimada foram resultados referentes às estimativas médias, obtidas quando máscara preta quando em centímetros, da profundidade ou relevo apresentada na posição vertical e julgada da máscara côncava preta para cada uma pelos observadores como totalmente das categorias de profundidade. Estão côncava $(\mathrm{C} 1)$ e as menores médias foram representadas todas as estimativas para a atribuídas à máscara apresentada na máscara côncava preta iluminada por posição vertical e classificada pelos baixo, totalizando 80 apresentações do observadores como plana (C3).

estímulo. As maiores médias da 


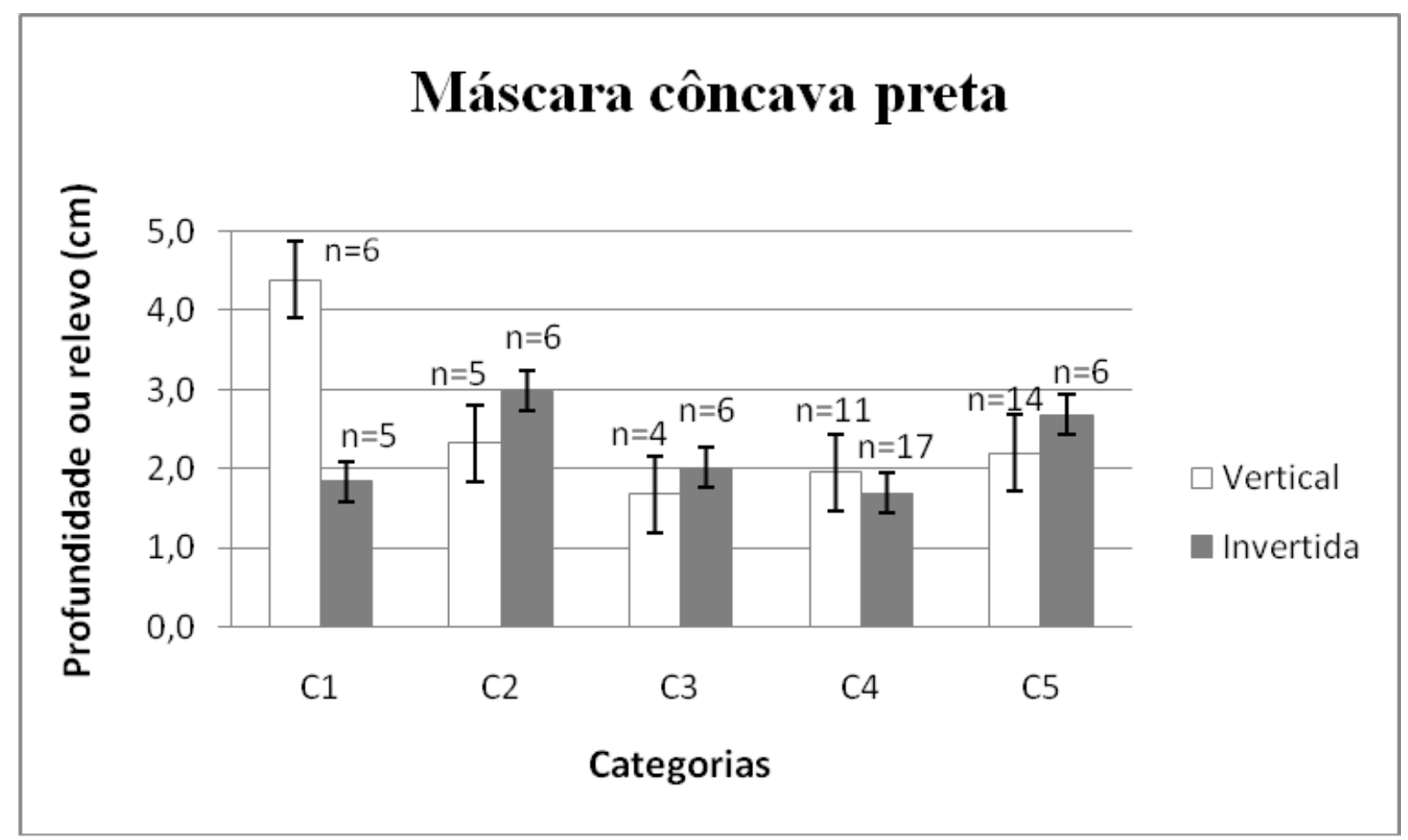

Figura 4: Estimativas médias, em centímetros, da profundidade ou relevo da máscara côncava preta para as categorias totalmente côncava $(\mathrm{C} 1)$, moderadamente côncava $(\mathrm{C} 2)$, plana $(\mathrm{C} 3)$, moderadamente convexa (C4) e totalmente convexa (C5), em 80 apresentações do estímulo.

O teste estatístico ANOVA de medidas repetidas não revelou efeitos principais significativos da luminosidade $[\mathrm{F}(1,39)=1,82 ; \mathrm{p}>0,05]$ e da posição $[\mathrm{F}$ $(1,39)=1,84 ; p>0,05]$ para as atribuições métricas da profundidade ou relevo das máscaras côncavas. Também não houve interação entre estes fatores $[\mathrm{F}(1,39)=1$, $0,36 ; p>0,05]$. Apesar desta diferença não ser significativa, pode-se observar um fato curioso na Figura 5, que representa as estimativas médias de profundidade ou relevo atribuído às três máscaras de diferentes luminosidades. A máscara branca recebeu, em média, as maiores estimativas de profundidade para os julgamentos das mesmas como totalmente convexas: $\mathrm{C} 5=3,12 \mathrm{~cm}$. Em contrapartida, a máscara preta obteve as menores estimativas para os julgamentos das máscaras como totalmente convexas: $\mathrm{C} 5=$ $2,52 \mathrm{~cm}$. Por outro lado, quando as máscaras côncavas foram categorizadas como totalmente côncavas, a máscara preta obteve as maiores magnitudes métricas da profundidade percebida, $\mathrm{C} 1=3,63 \mathrm{~cm}$, contrariamente à máscara branca, que obteve as menores estimativas para a categoria: $\mathrm{C} 1=2,39 \mathrm{~cm}$. 


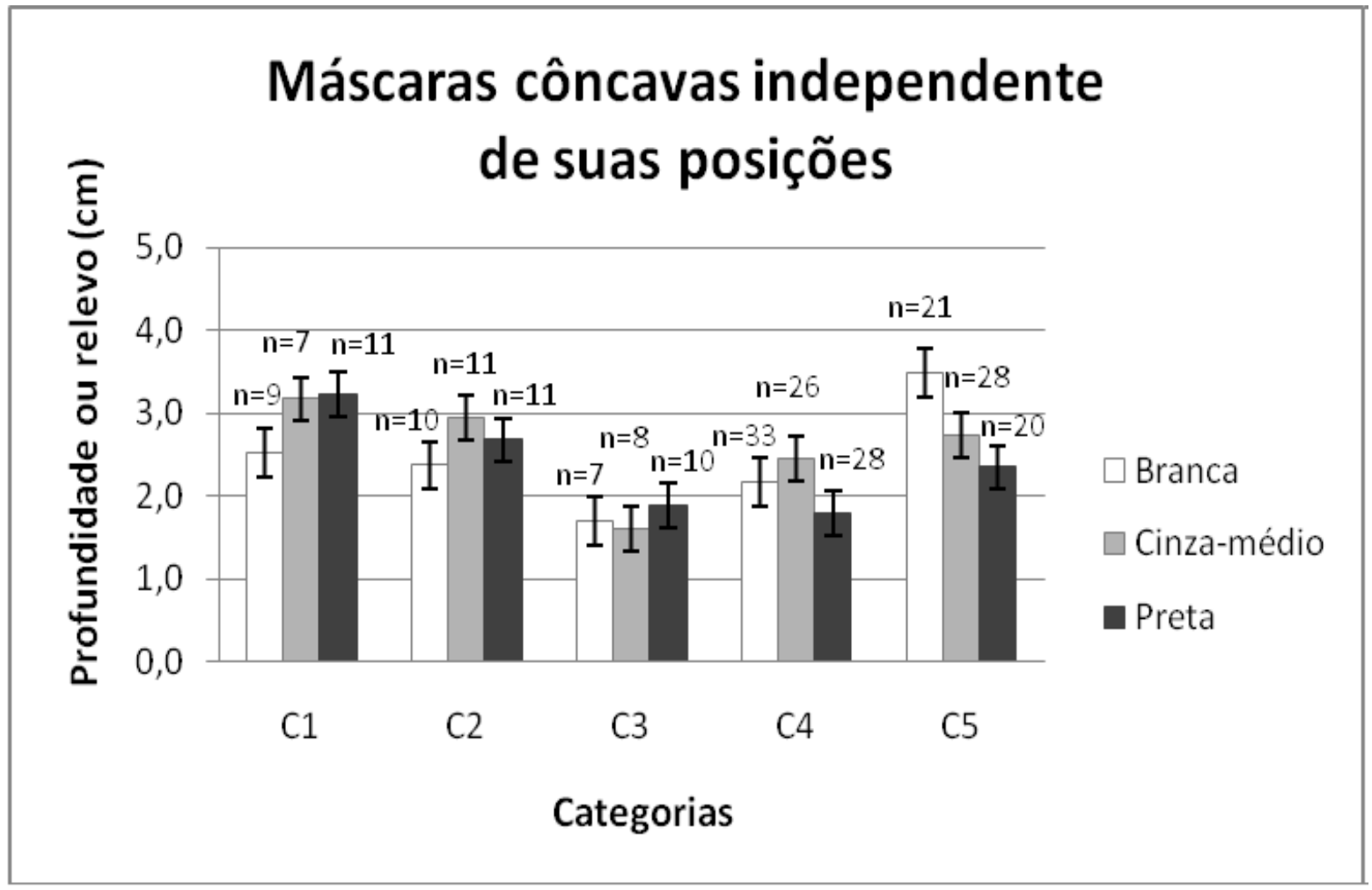

Figura 5: Estimativas médias, em centímetros, da profundidade ou relevo das máscaras côncavas branca, cinza médio e preta para as categorias totalmente côncava (C1), moderadamente côncava (C2), plana (C3), moderadamente convexa (C4) e totalmente convexa (C5), em 240 apresentações dos estímulos.

\section{Discussão}

Os resultados encontrados confirmaram a prevalência da percepção de convexidades diante da máscara côncava. Em $65 \%$ do total de apresentações das máscaras côncavas, os observadores fizeram a inversão monocular de profundidade, percebendo-as como convexas. Os observadores tenderam a realizar a inversão quando perceberam as máscaras côncavas como planas, em 10,42\% das apresentações dos estímulos. Destaca-se a sobreposição dos processos cognitivos, top-down, sobre os inputs sensoriais, bottom-up, na ilusão da máscara côncava, conforme observado por Gregory, (1997).

Curiosamente, foram atribuídas estimativas métricas de profundidade para as máscaras côncavas percebidas como planas. Esses resultados remetem à 
atribuição de profundidade mesmo diante de um estímulo plano, bidimensional. Por exemplo, frente a uma imagem bidimensional, os indivíduos podem levar em consideração os aspectos de profundidade e relevo, aspectos estes típicos de objetos tridimensionais.

O posicionamento da máscara côncava não se constituiu em fator determinante para a percepção monocular de sua profundidade ou relevo. Entretanto, as análises descritivas das porcentagens de respostas mostraram que, apesar da maioria dos observadores ter percebido as máscaras côncavas na posição invertida como convexas, as taxas de atribuições à categoria "côncava" foram maiores nesta condição de observação do que para as máscaras na posição vertical, independente das variações de brilho. Ademais, as máscaras côncavas na posição invertida foram percebidas mais vezes como planas para todas as 3 condições de brilho das máscaras. Mesmo com a percepção ilusória sendo predominante, houve uma tendência em perceber as máscaras posicionadas de cabeça para baixo como mais achatadas e côncavas. Esses resultados sugerem a importância dos conhecimentos prévios do indivíduo sobre a percepção ilusória da máscara côncava. Hill e Bruce (1994), Papathomas e Bono (2004) e Hill e Johnston (2007) revelaram ser a posição invertida da máscara côncava um possível fator capaz de dificultar a percepção ilusória, pois os observadores precisam estar mais afastados da máscara para perceber a ilusão. Além disso, esteogramas das as máscaras côncavas posicionadas de cabeça para baixo foram percebidos como mais achatadas na pesquisa de Quaglia e Fukusima (2015). Porém, a posição invertida não seria um fator inibidor da ilusão, visto a sua ocorrência a despeito do posicionamento da máscara côncava, mas sim tornaria a ilusão menos proeminente.

Não foram observadas diferenças estatísticas significativas nas atribuições, em centímetros, da profundidade ou relevo da máscara côncava frente às variações de luminosidade ou brilho. No entanto, quando realizaram a inversão visual da profundidade, os participantes atribuíram os maiores comprimentos da ponta do nariz à base da face para a máscara côncava branca e os menores comprimentos em centímetros para a máscara côncava preta. Curiosamente, quando não fizeram a inversão, os observadores emitiram os maiores comprimentos para a máscara côncava preta e os menores para a branca, percebendo-as como moderadamente e plenamente côncava. Estes resultados não possuem precedentes na literatura uma vez que nenhuma pesquisa anterior comparou a 
ESTHER SAMPAIO SANTOS, LÍVIA DA SILVA BACHETTI, MARIA AMÉLIA CESARI QUAGLIA, BRANDA GARCIA DA SILVA, CAIO RAFAEL SILVEIRA

profundidade em centímetros de máscaras côncavas com diferentes variações de brilho.

\section{Conclusões}

No presente estudo, a maioria dos participantes realizou a inversão visual das máscaras côncavas na condição monocular. A percepção das máscaras côncavas como sendo convexas não foi influenciada pelo posicionamento vertical ou invertido ou pela coloração das mesmas como branca, cinza-médio e preta. Contudo, mesmo quando julgadas como planas, estimativas métricas profundidade foram imputadas às máscaras. Além disso, quando observadas as três máscaras nas posições vertical e invertida, percebeu-se que a porcentagem de participantes que avaliou as máscaras como sendo côncavas e planas foi maior quando estas estavam dispostas na posição invertida, ou seja, de cabeça para baixo. Outro resultado interessante foi que, quando os observadores fizeram a inversão monocular de profundidade, menores médias de comprimentos em centímetros, da ponta do nariz à base da máscara, foram imputados para a máscara côncava preta e maiores médias de comprimentos para a máscara côncava branca. Por outro lado, os observadores que não realizaram a inversão estimaram menores comprimentos para a máscara côncava branca e maiores comprimentos para a máscara côncava preta.

Os resultados deste estudo não foram comparados com pesquisas anteriores devido à ausência de estudos que investigassem a estimativa em centímetros da percepção de profundidade ou relevo da máscara côncava em diferentes condições de brilho. Este fator demonstra a necessidade da realização de mais estudos sobre a ilusão da máscara côncava em diferentes condições de apresentação do estímulo. Além disso, reforça a importância da presente pesquisa para a ampliação do corpo de conhecimento a respeito deste fenômeno ilusório, bem como dos processos psicobiológicos básicos de percepção e cognição.

\section{Referências}

Baldo, M. V. C., \& Haddad, H. (2003). Ilusões e a percepção. Revista Brasileira de Psiquiatria, 25(Supl. II), 6-11. https://doi.org/10.1590/S1516-44462003000600003

Darwin, C. (1998). The descent of man. Amherst, NY: Prometheus (Obra original publicada em 1871). 
Gregory, R. L. (1997). Knowledge in perception and illusion. Philosophical Transactions of the Royal Society B: Biological Sciences, 35 (1358), 1121-1128. https://doi.org/10.1098/rstb.1997.0095

Hill, H., \& Bruce, V. (1993). Independent effects of lighting, orientation, and stereopsis on the hollow-face illusion. Perception, 22(8), 887-897. https://doi.org/10.1068/p220887

Hill, H., \& Bruce, V. (1994). A comparison between the hollow-face and "hollow-potato" illusions. Perception, 23, 1335-1337. https://doi.org/10.1068/p231335

Hill, H., \& Johnston, A. (2007). The hollow-face illusion: object-specific knowledge, general assumptions or properties of the stimulus. Perception, 36(2), 199-223. https://doi.org/10.1068/p5523

Papathomas, T. V., \& Bono, L. M. (2004) Experiments with a hollow mask and a reverspective: Topdown influences in the inversion effect for a 3-D stimuli . Perception, 33(9), 1129-1138. https://doi.org/10.1068/p5086

Quaglia, M. A. C., \& Fukusima, S. S. (2009). Cor, iluminação e orientação do reverso de uma máscara facial não afetam a ilusão da máscara côncava. Estudos de Psicologia, 14(2), 97-105. https://doi.org/10.1590/S1413-294X2009000200002

Quaglia, M. A. C. \& Fukusima, S. S. (no prelo). Efeitos da Cor, Iluminação e Rotação na Ilusão Estereoscópica da Máscara Côncava. Psicologia: Reflexão e Crítica, 28(2), 213-221.

Schneider, U., Leweke, F. M., Niemcyzk, W., Sternemann, U., Bevilacqua, M., \& Emrich, H. M. (1996). Impaired Binocular Depth Inversion in Patients with Alcohol Withdraw. Journal of Psychiatric Research, 30(6), 469-474. https://doi.org/10.1016/S0022-3956(96)00031-3

Yoshida, H. (2006). The effects of facial texture, stimulus orientation and light direction on the hollow-face illusion. Bulletin of the Graduate School of Education Hiroshima University. Education and Human Science, 55, 321-329.

\section{Os autores:}

Esther Sampaio Santos, doutoranda em Applied Health Sciences, Programa de Applied Health Sciences, Brock University. St. Catharines, Canadá. E-mail: esther.sampaio2@yahoo.com.br

Lívia da Silva Bachetti, doutora em Psicobiologia, Universidade de São Paulo, Ribeirão Preto, São Paulo, Brasil. E.mail: livbachetti@yahoo.com.br

Maria Amélia Cesari Quaglia, docente do Programa de Pós-graduação em Psicologia, Universidade Federal de São João del-Rei, São João del-Rei, Minas Gerais, Brasil. E.mail: melinha@ufsj.edu.br

Branda Garcia da Silva, psicóloga, Programa de Graduação em Psicologia, Universidade Federal de São João del-Rei, São João del-Rei, Minas Gerais, Brasil. E-mail: branda.cax@gmail.com

Caio Rafael Silveira, psicólogo, Programa de Graduação em Psicologia, Universidade Federal de São João delRei, São João del-Rei, Minas Gerais, Brasil. E.mail: caio-rafael-@ hotmail.com

Recebido em: 31/10/2017.

Aprovado em: 27/12/2017. 